\section{Perception by cebus monkeys: I. Psychophysical judgments of minimal cylindrical volume differences by nonhuman and human subjects*}

\author{
HENRY G. MASTERS and CATHY PODGORSKI \\ Juniata College, Huntingdon, Pa. 16652
}

Previously reported data have shown that monkeys can make visual discriminations quite well in three-dimensional space. But none have investigated the minimal space parameters which are necessary for a monkey to perceive a three-dimensional space. In the present experiment, the method of constant stimulus differences was used to assess both cebus monkey and human psychophysical judgments for minimal cylindrical volume differences. The data yielded a difference threshold of $3.7 \mathrm{~mm}$ for the cebus monkeys and a difference threshold of less than $1 \mathrm{~mm}$ for the human Ss. This species difference in thresholds is contrary to previously reported data.

This is the first experiment in a study of three-dimensional space as perceived by cebus monkeys. Three-dimensionality was defined here as that space which is delineated by the dimensions of height, width, and depth. In relating this to the cebus, it seemed important to ask just what specifically constitutes height, width, and depth for cebus monkeys. Recently, Zimmermann \& Hochberg (1971) have suggested that infant rhesus monkeys can respond to depth by observing the intersection of two planar surfaces which are at right angles to each other. This notion suggested that the monkeys could perceive three fundamental planar surfaces: the frontal, the horizontal, and the median planes (Gardner, 1964). The present experiment dealt with differing heights associated with cylindrical volume, as they were presented in the frontal plane relative to the cebus monkey's line of sight. Davis \& McDonald (1963) also presented cylinders differing in height to rhesus monkeys. Though their cylinders were always presented in the frontal plane relative to gravity, and not relative to the monkey's line of sight, their data are still relevant to the present study. They reported that adult rhesus monkeys can apparently discriminate cylindrical heights differing by approximately $1.37 \mathrm{in}$. They obtained this result by utilizing a three-object oddity problem where the two outer objects functioned as standard heights, and the center (not displaced) objects functioned as the comparison stimuli. When the height

*This study was supported by a grant from the Grass Foundation of Quincey. Mass. The authors also wish to thank Sharon Vanderhei. Steven Grange, and James Murray for their help in constructing the apparatus. of the center object was less than 1.37 in. higher than the short standard (.75 in.), the monkey selected the tall standard ( $3.50 \mathrm{in}$.) as odd, and when the height of the center object was greater than $1.37 \mathrm{in}$. above the short standard, the monkey selected the short standard as odd. Although this study did utilize height differences associated with cylindrical volume, it did not address itself to the rather interesting question of assessing the minimal cylindrical height difference which could be discriminated by monkeys. The present experiment specifically addressed itself to this question by assessing the difference threshold for cylindrical volume. In addition, since humans have about the same visual acuity as do cebus monkeys (Johnson, 1914) and rhesus monkeys (Walters et al, 1960), they all should have a similar difference threshold magnitude for cylindrical stimulus tray; SV, side view; SUP, support. height. The present experiment also compared these difference threshold magnitudes, under comparable conditions, for both cebus monkeys and human Ss.

\section{SUBJECTS}

The Ss were four female cebus apella, approximately 5 years old, weighing 4-41/2 lb. All had received previous training in height discrimination of cylinders prior to the present experiment, reaching a criterion of 20 out of 24 correct responses. Two Ss were trained to pick the shorter object, two the taller object. The Ss were not deprived of food during the test period.

The human Ss were 15 students, 11 females and 4 males, whose mean age was 19 years. The Ss were naive except for being told that this was an experiment in visual perception.

\section{APPARATUS FOR \\ CEBUS MONKEYS}

The apparatus was a Wisconsin General Test Apparatus (WGTA) (Schrier et al, 1965) painted light blue. The presentation tray for the cylinders was painted neutral gray and was set at a $45 \cdot \mathrm{deg}$ angle (Fig. 1). The difference between the two foodwells on the tray was 8 in., center to center. The stimulus objects were wooden cylinders, $11 / 4 \mathrm{in}$. in diam, and painted blue, yellow, green, or maroon. The given heights for the noncritical trials for any one color were (in millimeters ): $50,52,54,66,68,55$, $56,57,58,59,60,61,62,63,64$. In total, there were 17 objects for any one color. The $60-\mathrm{mm}$ cylinder was used as a standard for the critical trials. In other words, all cylinder heights in the critical trials were of the same color and compared against the $60 \mathrm{~mm}$ standard (i.e., blue comparison, object-blue standard; yellow comparison, object-yellow

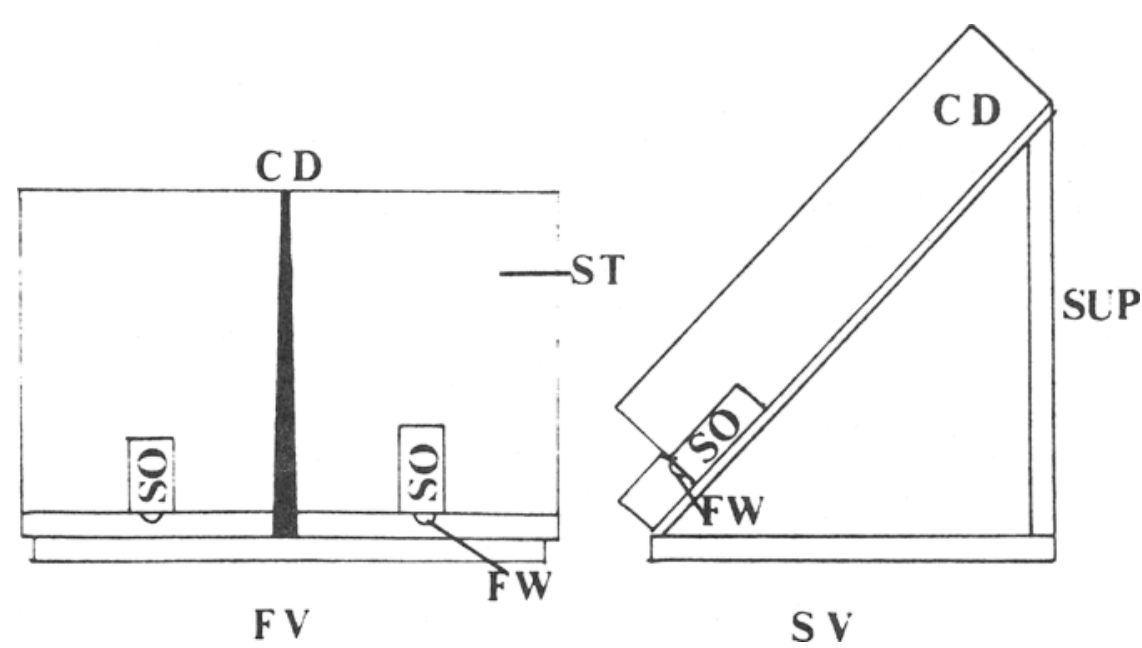

Fig. 1. The stimulus tray used in the Wisconsin General Test Apparatus. Key: CD, center divider; SO, stimulus object, FW, foodwell, FV, front view; ST, 
Table 1

\begin{tabular}{ccc}
$\begin{array}{c}\text { Group 1 } \\
(\mathrm{mm})\end{array}$ & $\begin{array}{c}\text { Group 2 } \\
(\mathrm{mm})\end{array}$ & $\begin{array}{c}\text { Differ- } \\
\text { ence in mm }\end{array}$ \\
\hline $61-60$ & $59-60$ & 1 \\
$58-60$ & $62-60$ & 2 \\
$57-60$ & $63-60$ & 3 \\
$64-60$ & $56-60$ & 4 \\
$65-60$ & $65-60$ & 5 \\
\hline
\end{tabular}

standard, etc.). Raisins and diced apples of approximately the same size were used as reinforcers for the monkeys.

\section{APPARATUS FOR HUMAN SS}

This apparatus consisted of two chairs and the presentation tray from the WGTA, which was placed on a small table standing approximately 15 in. from the floor. The cylinders used here were the same as those used for the critical trials with the monkeys. Since a $\mathrm{S}$ was to be tested at three different distances in front of the presentation tray (corresponding to the front, middle, and back positioning of the monkeys in the WGTA), each distance was indicated on the floor by masking tape. A pencil at the bottom of the S's chair pointed to a red dot on the floor which served to align the chair and $S$ to the center of the presentation tray. A sufficiently large piece of cardboard was placed in front of the stimulus tray to function as a stimulus screen.

\section{PROCEDURE FOR CEBUS MONKEYS}

The Ss had been previously trained to the tray and stimulus objects (Rinehart ${ }^{1}$ ); therefore, testing began immediately, utilizing the psychophysical method of constant stimulus differences (Bell, Noble, \& Daves, 1971). A trial consisted of one pairing of two objects differing in height but of the same color. There were 30 trials per session, one session per day for 20 days. The first seven sessions consisted of 10 critical presentations and 20 noncritical presentations per session. During these seven sessions, it became apparent that the monkeys could work twice as many critical trials and still perform at a high level. Therefore, Sessions 8-20 consisted of 20 critical and 10 noncritical presentations per session. The critical trials consisted of the pairings divided into Group 1 and Group 2 stimuli (Grange ${ }^{2}$ ), as shown in Table 1. Group 1 and Group 2 stimuli were presented on alternating days. The remaining pairings (noncritical trials) involved stimuli with 10-20-mm differences, i.e., 52-70, 54-64. However, objects of $55,56,57$, 58,59 , and $60 \mathrm{~mm}$ did not appear in any of these pairings. During the first seven sessions, each pairing in Group 1 and Group 2 was presented twice. In Sessions 8-20, each pairing in Groups 1 and 2 was presented four times, once in each color. The order of object pair presentation was randomized, but the position of the reinforcer and the placement of the correct object was determined by a Gellerman series (Hilgard, 1951). For all noncritical trials, the color and height differences were selected randomly and the placement of the reinforcer was again determined by the Gellerman series. A noncorrectional procedure for incorrect choices was employed throughout the experiment.

PROCEDURE FOR HUMAN SS

The $S$ was seated in front of the screened presentation tray and given the following instructions: "This is an experiment in visual perception. In front of you, you see a tray. Two objects will be placed upon the tray (demonstrate). You are to indicate, by raising the appropriate hand, which one of the objects is taller ('shorter' for half of the group) than the other object. The experimenter will indicate a correct choice by a verbal response of 'correct.' For an incorrect response, the experimenter will say nothing. You are to remain still throughout the trials. The removal of the screen in front of the objects will signal the beginning of each trial. Are there any questions?" If there were no questions, the experiment began.

First, the $E$ checked the position of the S's chair, which had to be placed in one of three positions: (1) front, 6 in. from tray, (2) middle, $16 \frac{1}{4}$ in. from tray, and (3) back, 29 in. from tray. Next, the $S$ was asked to lean forward and touch his head to a board, or to the E's hand in the front position, in order to set the head at the proper distance from the presentation tray. The order of the S's chair positions (i.e., front, middle, back, back, middle, front; middle, front, back) was determined randomly for each $S$. The $E$ used only the objects constituting critical trials for the monkeys, and also determined randomly the order of object pair presentation and the position of the correct object. Object colors appeared an equal number of times. Each $S$ participated in only one test session. Sixty trials were given per test session, 20 trials in each chair position. According to random assignment, eight Ss judged the taller objects and seven $S s$ judged the shorter objects. Group 1 and Group 2 stimuli (Table 2) were massed together, each one being presented twice in each chair position. A verbal response of "correct" was given to the $S$ as a reinforcer, and the absence of a verbal "correct" from the $E$ designated an incorrect response on the part of the $S$.

Since the cebus monkeys' performance (percent correct judgments) on Group 1 and Group 2 critical trials stimuli did not differ significantly for tall judgments $(t=$ $1.304, \mathrm{df}=4$ ) or for short judgments $(t=.377, \mathrm{df}=4)$, these Group 1 and Group 2 data were pooled. A test (Edwards, 1960) of these pooled data for overall tall judgments vs overall short judgments also yielded no statistical significance $(\mathrm{t}=.674$, $\mathrm{df}=$ 8 ), therefore, these data were again pooled to give the overall critical trial performance (percent correct) for the cebus monkeys. These data were then tested against the percent correct performance of the human Ss. No tests for Group 1 and Group 2 stimuli, for tall judgments vs short judgments, or for performance at the three test distances were necessary for the human Ss because of their extremely high level of performance (Table 2). The $t$ test for cebus monkeys vs human performance was statistically significant $(\mathrm{t}=8.813, \mathrm{df}=8$, $p<.025$ ). Figure 2 shows the percent correct responding for the cebus and the human Ss. This figure also gives the difference threshold value of $3.70 \mathrm{~mm}$ for the cebus's height judgments concerning cylindrical volume (Bartley, 1970). Again, the high performance of the human Ss did not directly allow for a $75 \%$ correct criterion for a difference threshold determination, but it is evident that if finer gradations in stimulus object height had been presented to the human Ss, their difference thresholds for the height judgments concerning cylindrical volume would have been less than $1 \mathrm{~mm}$.

\section{DISCUSSION}

It appears that the difference threshold for the cebus monkeys is a stable threshold. This is based on the fact that the cebus's performance on the noncritical trials throughout testing averaged $86.31 \%$ correct judgments. The percent correct judgments for each of the monkeys were $96.25 \%, 91.75 \%, 87.00 \%$, and $70.25 \%$. This last percentage was for the monkey with the lowest performance score, yet her performance for the critical trial stimuli was still lower than her overall performance for the noncritical trial stimuli. Therefore, it does not appear

Table 2

Percent Correct Judgments of Critical Trials for Cebus Monkeys and Human Ss

Object

Height

\begin{tabular}{ccc}
$\begin{array}{c}\text { Differences } \\
\text { in mm }\end{array}$ & $\begin{array}{c}\text { Cebus } \\
\text { Monkeys }\end{array}$ & $\begin{array}{c}\text { Human } \\
\text { Ss }\end{array}$ \\
\hline 1 & 63 & 95 \\
2 & 63 & 99 \\
3 & 67 & 100 \\
4 & 78 & 100 \\
5 & 76 & 100 \\
\hline
\end{tabular}


that the larger difference threshold for the cebus as compared to the human Ss was due to poor overall performing on the part of the cebus. Since this is the case, it seems reasonable to state that the rhesus monkeys in the Davis \& McDonald (1963) study could, in fact, discriminate heights differing by approximately $1.37 \mathrm{in}$. Not only does this last value greatly exceed the difference threshold value of $3.7 \mathrm{~mm}$ for the cebus monkey, but species differences between cebus and rhesus monkeys have been reported to be minimal for performance on discrimination problems similar to those used to establish learning sets (Devine, 1970; Stevens, 1966). Further support for a performance similarity between the two species comes from anatomical data which state that cebus and rhesus monkeys have very similar visual systems (LeGros Clark, 1960).

The difference in the thresholds for cylindrical volume between cebus and human Ss was not expected, since it conflicts with the Johnson (1914, 1916) data. Even though his data were presented in terms of visual angle and the present data in terms of object height which subtends the angle, the visual threshold for the cebus in the present experiment could not equal the visual threshold for the human Ss. This is evident in that the human Ss, regardless of their distance from the stimulus objects, still yielded a difference threshold of less than $1 \mathrm{~mm}$. Granting the cebus the maximum distance of the restraining cage (the smallest visual angle possible here), which equaled the longest distance over which the humans had to judge, the difference threshold for the cebus was still far greater than that for the human Ss. One possible reason for this discrepancy is that Johnson used an acuity grating as a stimulus target, whereas the present study used the more sensitive vernier acuity task (Woodworth \& Schlosberg, 1954). This added task sensitivity was apparently able to separate the species' performance, whereas the less sensitive acuity grating could not. Both in the Johnson data (1916) and in the present experiment, the criterion for the difference threshold was $75 \%$ correct responses.

A brief word should be said concerning the testing of the human Ss at three different distances from the test tray. If the performance of the human Ss was equal to that of the cebus, as was suggested by Johnson (1916), then comparing the performance of the humans to the cebus at each of the test distances would have constituted a systematic control for the fact that the free-moving cebus could have judged

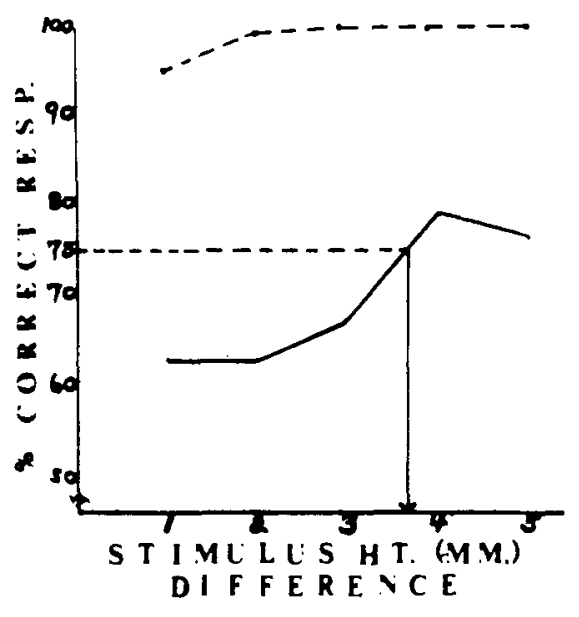

Fig. 2. Percent correct responding for cebus monkeys (dots) and human Ss (circles) as a function of stimulus object height differences (millimeters). The arrow indicates the difference threshold value for the cebus monkeys.

the stimuli at any distance from the front to the back of the testing cage. As it turned out, the human Ss performed at such a high level at all three distances that no separate comparisons could be made. Therefore, the comparison between the species' judgments has been discussed in terms of the farthest viewing point for the cebus in the testing cage, since this point would yield the cebus's maximum visual sensitivity (i.e., the smallest visual angle for a constant stimulus height).

One last point that should be mentioned concerns the fact that the cebus reached for and obtained a food reinforcement from a foodwell at the bottom of the stimulus object, whereas the human Ss only reached out and pointed to the stimulus objects which they selected. It is possible that the cebus's performance may have been poorer than the human Ss' performance because the cebus Ss were looking at the base of the objects instead of at the tops of the objects, where the height differences had to be discriminated. Yet, McClearn \& Harlow (Schrier, 1965) reported that for monkeys, a 2 -in. distance between reinforcer and stimulus cue resulted in performance levels around $95 \%$ correct. The cylindrical stimulus objects in the present study ranged between 2 and $2 \frac{3 / 4}{4}$. in height. Since these cylindrical test object heights, which set the distances between the reinforcer and the stimuli difference, were within the critical distances established by the McClearn and Harlow data, it is very doubtful that these distances affected the cebus's judgments any more than they affected the human judgments.

The question that was raised at the outset of this paper was: How high above a horizontal plane must an object in the frontal plane be placed in order for cebus monkeys and humans to perceive it as being different from the horizontal plane. The answer from the present study indicates that in the present viewing situation, a minimal height difference of $3.7 \mathrm{~mm}$ is necessary for cebus monkeys and one of less than $1 \mathrm{~mm}$ is necessary for humans. Further research in this laboratory should yield data on the minimal width and depth that can be perceived by these two species. These data will then define for the present viewing situation the minimal criterion (in millimeters) for height, width, and depth which, taken together, will specify the minimal conditions for visual three-dimensional space.

\section{REFERENCES}

BARTLEY, S. H. Principles of perception. (2nd ed.) New York: Harper \& Row, 1969.

BELL, R. A., NOBLE, N. E., \& DAVES, W. $F$. Echolocation in the blinded rat. Perception \& Psychophysics, 1971, 10. $112 \cdot 114$.

DAVIS, R. T. \& McDONALD, A. L. Perception of oddity by monkeys as a function of aging and radiation. Psychological Reports, 1962, 11, 383-386.

DEVINE, J. V. Stimulus attributes and training procedures in learning-set formation of rhesus and cebus monkeys. Journal of Comparative \& Physiological Psychology, 1970, 73,62-67.

EDWARDS, A. L. Experimental design in psychological research. New York: Holt, Rinehart \& Winston, 1960.

GARDNER, E. Fundamentals of neurology. Philadelphia: Saunders, 1964.

HILGARD, E. Methods and procedures in the study of learning. In $S$. S. Stevens (Ed.), Handbook of experimental psychology. New York: Wiley, 1951.

J O H N S O N, H. M. V is u a l pattern-discrimination in the vertebrates: I. Problems and methods. Journal of Animal Behavior, 1914, 4, 319-339.

JOHNSON, H. M. Visual pattern discrimination in vertebrates: III. Effective differences in width of visible striae for the monkey and the chick. Journal of Animal Behavior, 1916, 6, 169-187.

LeGROS CLARK. W. E. The antecedents of man. Chicago: Quadrangle Books, 1960. SCHRIER, A. M., HARLOW, H. F., \& STOLLNITZ, F. Behavior of nonhuman primates. Vol. 1. New York: Academic Press, 1965

STEVENS, D. A. A comparison of learning in rhesus monkeys, cebus monkeys, lemurs, and Burmese cats. (Doctoral dissertation. University of Oregon) Ann Arbor, Mich: University Microfilms, 1966. No. 66-632.

WATERS, R. H., RETHLINGSHOFER, D. A., \& CALDWELL, W. E. Principles of comparative psychology. New York: McGraw-Hill, 1960.

WOODWORTH, R., \& SCHLOSBERG, H. Experimental psychology. New York: Holt, Rinehart \& Winston, 1954

ZIMMERMANN, R. R., \& HOCHBERG,J. 
The facilitation of picture discrimination leaming in the neonatal monkey and probably vice versa. Psychonomic
Science, 1971, 24, 239-241.

$$
\text { NOTES }
$$

1. B. Reinhart, personal communication,
1970 .

2. S. Grange, personal communication 1970 . 